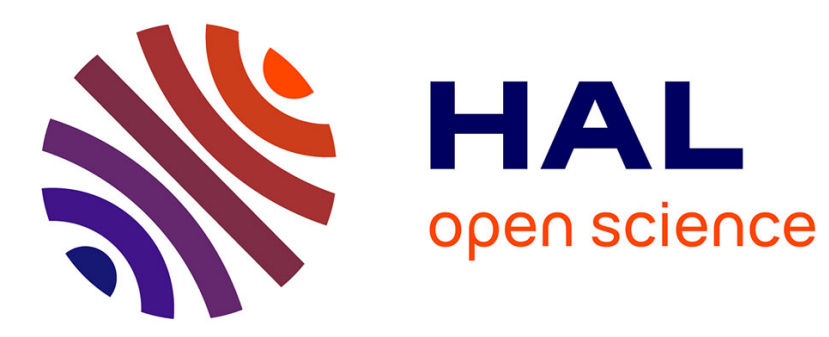

\title{
Implementation and Analysis of FMIPv6, an Enhancement of MIPv6
}

\author{
Johan Pieterse, Nathalie Mitton, Riaan Wolhuter
}

\section{To cite this version:}

Johan Pieterse, Nathalie Mitton, Riaan Wolhuter. Implementation and Analysis of FMIPv6, an Enhancement of MIPv6. 4th International Conference on Ad Hoc Networks (AdHocNets), Oct 2012, Paris, France. hal-00740373

\section{HAL Id: hal-00740373 https://hal.inria.fr/hal-00740373}

Submitted on 9 Aug 2013

HAL is a multi-disciplinary open access archive for the deposit and dissemination of scientific research documents, whether they are published or not. The documents may come from teaching and research institutions in France or abroad, or from public or private research centers.
L'archive ouverte pluridisciplinaire HAL, est destinée au dépôt et à la diffusion de documents scientifiques de niveau recherche, publiés ou non, émanant des établissements d'enseignement et de recherche français ou étrangers, des laboratoires publics ou privés. 


\title{
Implementation and Analysis of FMIPv6, an Enhancement of MIPv6
}

\author{
Johan Pieterse $^{1}$, Riaan Wolhuter ${ }^{2}$, and Nathalie Mitton ${ }^{3}$ \\ 1 Department of Electronic Engineering, University of Stellenbosch, South Africa \\ 7600 , \\ 15041077@sun.ac.za \\ 2 Department of Electronic Engineering, University of Stellenbosch,South Africa \\ 7600 , \\ wolhuter@sun.ac.za \\ 3 Inria Lille - Nord Europe, France \\ nathalie.mitton@inria.fr
}

\begin{abstract}
The initial IP Mobility protocol was first presented in 1993 for IPv4. The Mobile IP protocol solves the TCP/IP Layer 3 mobility, by assigning a permanent IP address to the mobile node. Mobile IP consists of both MIPv4 and MIPv6, but IPv4 has a couple of drawbacks, the main one being IP address exhaustion, making MIPv6 the future option for mobility protocol in IP Networks. The main goal of the mobility protocol is to enable network applications to operate continuously at the required quality of service for both wired and wireless networks. MIPv6 uses the existing IPv6 protocol to enable seamless roaming between different access points. MIPv6 on its own needs optimization techniques to improve the handover latency of the protocol and to minimize the latency. This paper proposes FMIPv6 protocol to minimize handover latency. Both MIPv6 and FMIPv6 protocols introduce some new terminologies as proposed by the Internet Engineering Task Force (IETF), which require prior familiarisation to understand the working of MIPv6 and FMIPv6.
\end{abstract}

Key words: MIPv6, FMIPv6, handover latency, Fast binding update, AR, NAR, PAR

\section{Background}

The Mobile IP protocol solves the TCP/IP Layer 3 mobility, by assigning a permanent IP address to the mobile node. Mobile IP consists of both MIPv4 and MIPv6, but IPv4 has a couple of drawbacks, the main one being IP address exhaustion, making MIPv6 the future option for mobility protocol in IP Networks [1].The main goal of the mobility protocol is to enable network applications to operate continuously at the required quality of service for both wired and wireless networks [2]. MIPv6 uses the existing IPv6 protocol to enable seamless roaming between different access points [2,3]. MIPv6 on its own needs optimization techniques to improve the handover latency of the protocol and to minimize the latency. FMIPv6 proposes some enhancements to minimize 
the handover latency of a MIPv6 network. The MIPv6 and FMIPv6 protocol also introduces some new terminologies as proposed by the Internet Engineering Task Force (IETF), which require prior familiarisation to understand the workings of MIPv6 and FMIPv6 [4].

\subsection{Internet Protocol version 6}

With the rappid growth of the internet the current IP version 4 is becoming exhausted and will make way for the "next generation" IP version 6 that is designed to enable ongoing expansion of the Internet. The continuous growth of the Internet requires an evolution of the overall IP architecture to accommodate new technologies that support increasing numbers of users, applications and services. In terms of IP services integrated into the architecture, IPv6 most notably offers integrated auto-configuration, expanded IP addresses, enhanced mobility, end-to-end security and quality-of-service (QoS). The design of IPv6 is intentionally targeted for minimal impact on upper and lower layer protocols by avoiding the random addition of new features [5].

- Large address space: IPv6 increases the IP address size from 32 bits to 128 bits, to support more levels of addressing hierarchy, a much greater number of addressable nodes, and simpler auto-configuration of addresses. A 'scope' field was added to the multicast addresses to improve the scalability of multicast routing. A new type of address called the 'anycast address' was also defined. This packet is used for sending a packet to any one of a group of nodes.

- Extensibility: IPv6 can easily be extended for new features by adding extension headers after the IPv6 header. Unlike options in the IPv4 header, which can only support 40 bytes of options, the size of IPv6 extension headers is only constrained by the size of the IPv6 packet.

- Better support for prioritized delivery: A new capability is added to enable the labelling of packets belonging to particular traffic 'flows' for which the sender requests special handling, such as non-default quality of service or 'real-time' service. And the IPv6 also has built-in support prioritized delivery, IPSec, and mobility [5].

\subsection{Mobile Internet Protocol version 6}

Mobile Node (MN): The MN is a node that moves between different networks, namely the home network and foreign networks.

Home Network (HN): The MN is permanently connected to this network. The subnet of this network corresponds to the home address of the MN and home agent.

Home Agent (HA): The home agent is a router in the HN responsible to forward packets destined for the MN when the MN has moved to a foreign network. Foreign Network (FN): This is the network to which the MN moves and attaches when not in the HN. 
Foreign Agent (FA): The foreign agent is a router in the FN to which a MN attaches when not in the HN. The FA assigns a care-of-address to the MN and is used to forward and receive packets destined for the MN.

Correspondent Node $(\mathbf{C N})$ : The $\mathrm{CN}$ is a node located somewhere in any network and communicates with the MN.

Care-of-Address (CoA): This address is a IPv6 address assigned to the MN via the foreign agent and can be a agent care-of-address, or a collocated careof-address. The MN uses this address to communicate when not in it's home network.

- Foreign Agent Care-of-Address (FA CoA): The MN gets the the IP of the foreign agent by use of Agent Advertisements.

- Co-located Care-of-Address (CCoA): The MN receives this IP when the foreign network temporarily assigns an IP to the MN using Router Advertisements, or Dynamic Host Configuration Protocol.

MIPv6 makes use of triangular routing and route optimization to forward packets to and from the MN [6]. The route optimization protocol enables the MN and the $\mathrm{CN}$ to send packets directly to each other via direct routing despite the changes in IP connectivity, by using tunneling. The main problem with MIPv6, is the handover delay when moving between nodes and it consists of the following delay components [7]:

$$
T_{T H O}=T_{H R D}+T_{C R D}+T_{L 2 D}+T_{R D D}+T_{R R D}+T_{D A D}
$$

Where:

$$
\begin{aligned}
& T_{T H O}=\text { Total Handover Delay } \\
& T_{H R D}=\text { Home Registration Delay } \\
& T_{C R D}=\text { Correspondent Registration Delay } \\
& T_{L 2 D}=\text { Layer } 2 \text { Handover Delay } \\
& T_{R D D}=\text { Router Discovery Delay } \\
& T_{R R D}=\text { Return Routability Delay } \\
& T_{D A D D}=\text { Duplicate Address Detection Delay }
\end{aligned}
$$

\subsection{Fast Mobile Internet Protocol version 6}

Access Router (AR): This router refers to the MN's default router.

Access Point (AP): The AP refers to the device that enable wireless connection to the $\mathrm{MN}$ and is a Layer 2 device connected to a IP subnet.

Previous Access Router (PAR): This router refers to the MN's default router prior to its handover.

New Access Router (NAR): This router refers to the MN's new router subsequent to its handover. 
Previous Care-of-Address (PCoA): The valid IP address on the PAR's subnet.

New Care-of-Address (NCoA): The valid IP address on the NAR 's subnet.

FMIPv6 attempts to enhancement the handover strategy in a MIPv6 network. The main goal of FMIPv6 is to configure a new Care-Of-Address (NCoA) or Previous CoA ( $\mathrm{PCoA}$ ) for the mobile node before the mobile node moves to the new access router. The FMIPv6 protocol enables a MN to request information about neighbouring AP's and the subnets information of AR's. There are two types of handovers that have been identified in the FMIPv6 protocol, namely Predictive and Reactive handover.

The MN sends a Router Solicitation for Proxy Advertisement (RtSolPr) to the current AR requesting information for a potential handover. The AR replies with a Proxy Router Advertisement (PrRtAdv) containing information about neighbouring links. This message also acts as a trigger for network-initiated handover. After the PrRtAdv was received, the MN formulates a prospective NCoA and sends a Fast Binding Update (FBU) to the PAR. The purpose of the FBU is to bind the PCoA to the NCoA so that the arriving packets can be tunnelled to the new location of the MN. The PAR sends a FBack to the MN and this means that the packet tunneling is already in progress by the time the MN attaches to the NAR. This scenario is called the "predictive" mode of operation. The MN will then send a Fast Neighbour Advertisement (FNA) as soon as the $\mathrm{MN}$ is connected to the NAR. This message is used to announce attachment between the MN and the NAR and to confirm the use of the NCoA. [5]

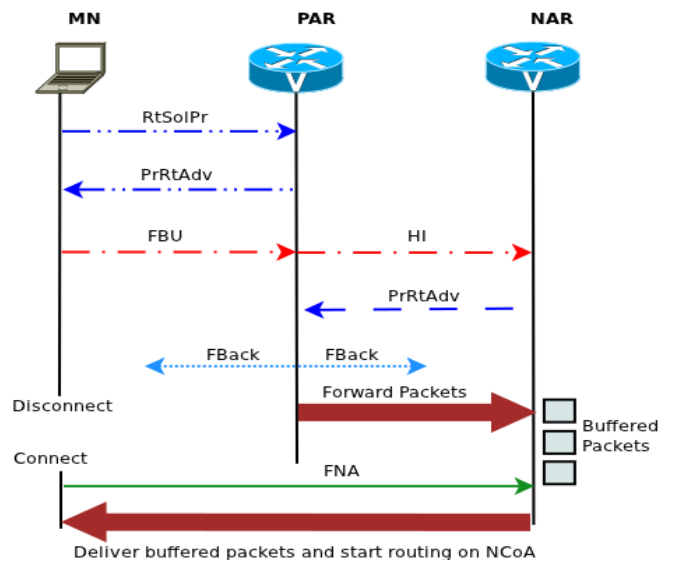

Fig. 1. FMIPv6 Handover Predictive

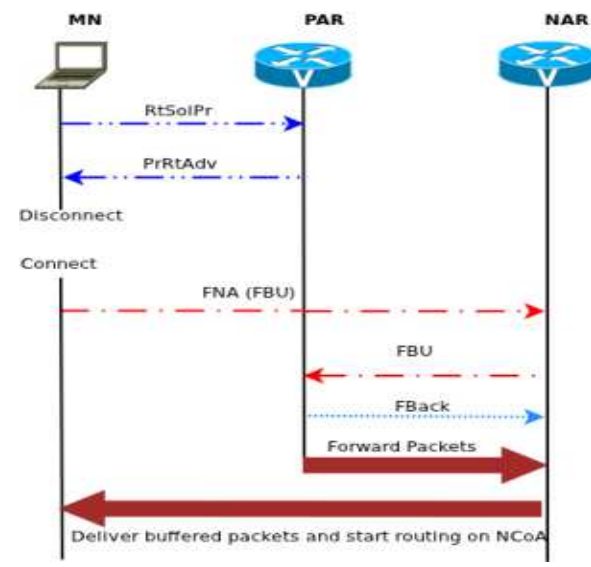

Fig. 2. FMIPv6 Handover Reactive

The reactive handover mechanism represents the case where the MN could not anticipate the handover. The reactive mode can be seen in Figure 2. In this case the MN was only able to react once the handover was already in progress. In the reactive case the FBU is send from the NAR's link and is encapsulated in 
the FNA message after the Layer 2 handover has completed. The NAR forwards the FBU to the PAR, this is followed by a HI/HACK exchange and the PAR then starts to tunnel packets to the NAR.

\section{Objectives}

The objectives of this investigation was to develop a test bed, in order to evaluate different handover strategies in a Mobile IPv6 network. This would also evaluate the capability of the IPv6 network protocol in a mobile network environment. Efficient handover strategies are important for MIPv6, as this is the main cause of packet loss thus reducing service quality in mobile networks. To reduce the handover latency FMIPv6 was implemented on the network to evaluate the improvements on the handover latency of MIPv6. After implementation of FMIPv6 the results of the FMIPv6 network was compared with those of the MIPv6 network to evaluate improvements of FMIPv6 on the network performance.

\section{Methodology}

Initially, the handover latency between access points in a WLAN IPv6 network was determined by simulating the network using Omnett++ Network Simulator. Next, the simulated network was built and MIPv6 implemented on the test bed for evaluation of the actual network. We consider a single MN moving between two AR's in two different subnets between the home network and a visited network in MIPv6. See Figure 3. After the MIPv6 network was functioning,we implemented FMIPv6 on the same network to evaluate the handover latency of the network with FMIPv6. Simulations and hardware performance of handover latencies could than be compared.

These complementary results were used to investigate different handover techniques and possible optimization of the current handover technique. After investigation of different handover techniques, FMIPv6 was implemented on the test bed to improve the handover latency of the MIPv6 network. The FMIPv6 protocol was tested by moving MN visiting new subnets link between PAR and NAR as seen in Figure 4. The performance measurement of the FMIPv6 network includes TCP/UDP throughput, packet loss and handover latency measurement with the Jperf network application.

\section{Implementation}

\subsection{MIPv6 network}

The implementation of the protocol was done on a IPv6 test bed, consisting of various Linux based PC's set up as routers. Figure 3 depicts the network topology of the test bed. Table 1 shows the hardware and software setup of 
Table 1. MIPv6/FMIPv6 Test Bed Setup

\begin{tabular}{|c|c|c|}
\hline Device name & Network Configuration & Software setup \\
\hline HA & $\begin{array}{l}\text { Consists of multiple nic's and IPv6 } \\
\text { forwarding is enabled to act as } \\
\text { router. }\end{array}$ & $\begin{array}{l}\text { Linux MIPv6 2.6.38 compiled ker- } \\
\text { nel, radvd } 1.7 \text { and MIPv6 UMIP } 0.4 \\
\text { home agent setup. }\end{array}$ \\
\hline FA & $\begin{array}{l}\text { Consists of multiple nic's and IPv6 } \\
\text { forwarding is enabled to act as } \\
\text { router. }\end{array}$ & $\begin{array}{l}\text { Linux 2.6.38-generic kernel and } \\
\text { radvd 1.7. }\end{array}$ \\
\hline $\mathrm{MN}$ & IPv6 802.11n access point & $\begin{array}{l}\text { Linux MIPv6 2.6.38 compiled ker- } \\
\text { nel and MIPv6 UMIP } 0.4 \text { mobile } \\
\text { node setup. }\end{array}$ \\
\hline $\mathrm{CN}$ & IPv6 ready IP Camera & $\begin{array}{l}\text { Linux MIPv6 } 2.6 .38 \text { compiled ker- } \\
\text { nel and MIPv6 UMIP } 0.4 \text { CN setup. }\end{array}$ \\
\hline CN Router & $\begin{array}{l}\text { Consists of multiple nic's and IPv6 } \\
\text { forwarding is enabled to act as } \\
\text { router. }\end{array}$ & $\begin{array}{lll}\text { Linux } 2.6 .38 \text {-generic } & \text { kernel and } \\
\text { radvd } 1.7 . & & \end{array}$ \\
\hline AP & IPv6 802.11n access point & $\begin{array}{l}\text { OpenWrt Firmware and Linux } 3.2 .5 \\
\text { compiled kernel with IPv6 enabled. }\end{array}$ \\
\hline $\mathrm{AR}$ & $\begin{array}{l}\text { Consists of multiple nic's and IPv6 } \\
\text { forwarding is enabled to act as } \\
\text { router. }\end{array}$ & $\begin{array}{l}\text { Linux MIPv6 2.6.38 compiled ker- } \\
\text { nel, radvd } 1.7 \text { and FMIPv6 daemon } \\
\text { running. }\end{array}$ \\
\hline
\end{tabular}

the various nodes. The MIPv6 stack used in the implementation, is the (UMIP) Mobile IPv6 stack for Linux [8]. The corresponding node consists of a IPv6-ready IP camera transmitting live video streaming to the MN. The live streaming is used to measure packet loss and the handover latency produced by the MIPv6 protocol, when the MN moves from one access point to another.

The network consists of three subnets as shown in Figure 3. IPv6 addresses are assigned by the routers using Router Advertisements broadcast messages. The Linux kernels for the MN,CN and HA was recompiled to include the MIPv6 extensions for the kernels. The access points are based on Omnima Embedded Linux Wifi boards, running Openwrt Linux distributions for embedded wireless devices.

\subsection{FMIPv6 network}

The implementation of the protocol was done on the MIPv6 test bed as already setup.The setup for the various hardware components can be seen in Table 1 . The MN will first move from the home network to AR1. From this point on, the FMIPv6 protocol will handle the handover between the PAR and the NAR, as seen in Figure 4. 


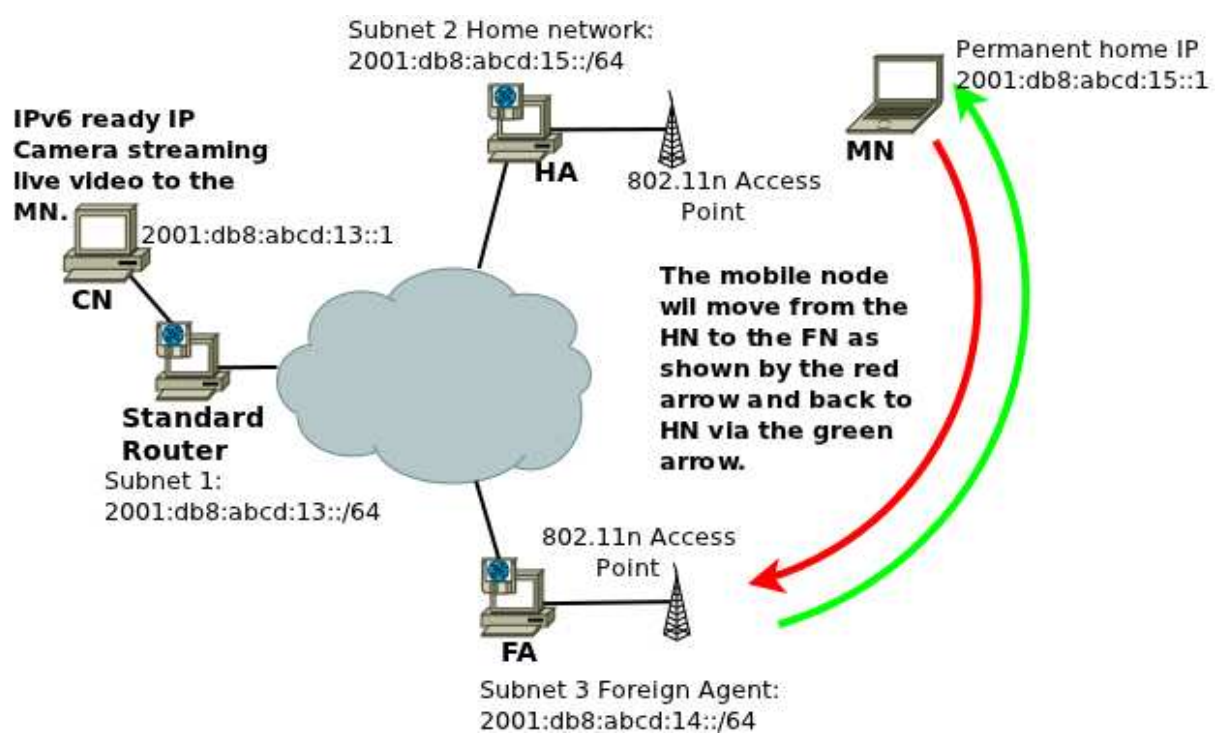

Fig. 3. MIPv6 network setup

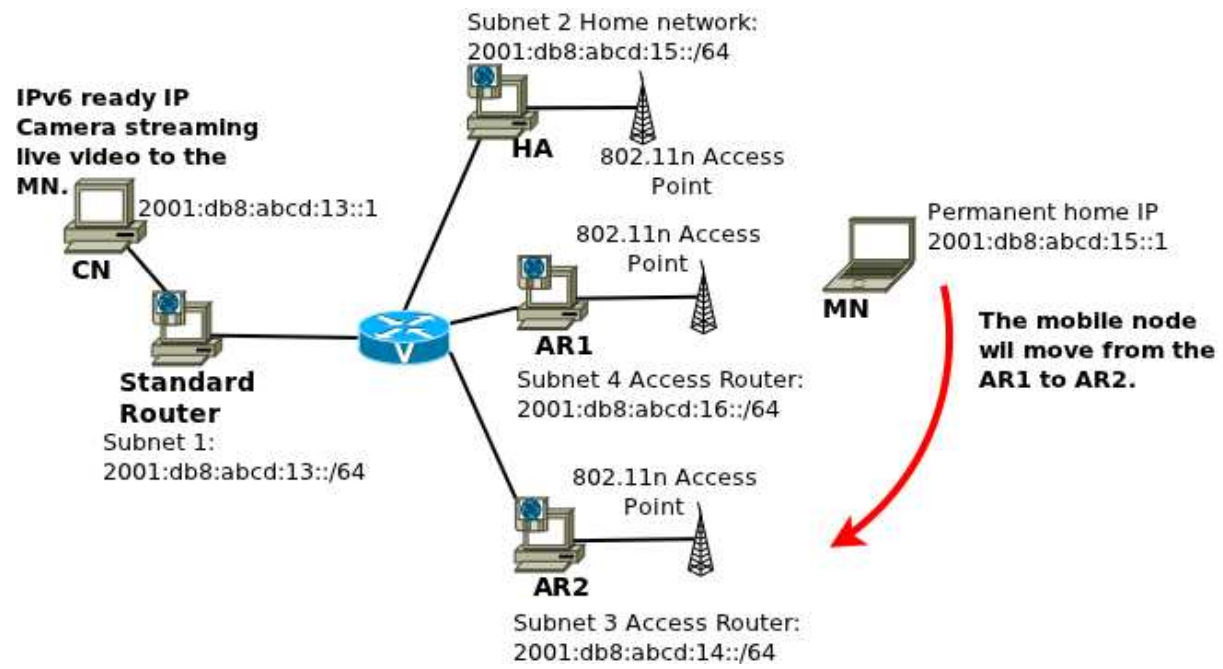

Fig. 4. FMIPv6 network setup

\section{Results}

The following results were captured using the Jperf application. Jperf is an application used to measure the jitter, throughput and bandwith for network protocols. [9] During the experiment, we transmit UDP traffic at the rate of 
$10 \mathrm{Mbps}$ and we use the Jperfs default values of packet size and buffer size for both UDP and TCP environment. For the TCP measurement we use the Jperfs default values for the TCP buffer length, TCP Windows Size, and TCP Max Segment Size. The the jeperf apllication the CN is setup as the server and the $\mathrm{MN}$ as the client.

\subsection{MIPv6 Test Bed}

The MIPv6 Test Bed was used to test the MIPv6 protocol on a physical level, the protocol was implemented and successful results were obtained from the test bed. The sought for results are in terms of protocol performance when live video is streamed to the mobile node and to investigate the affect of handover latency on real-time applications between the $\mathrm{MN}$ and $\mathrm{CN}$.

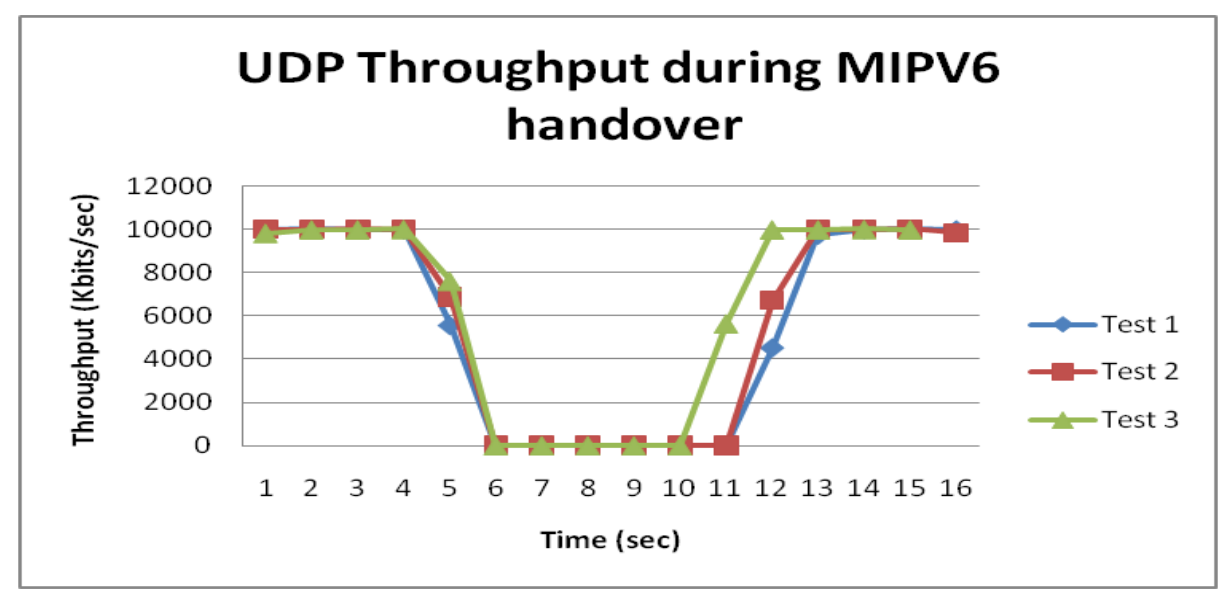

Fig. 5. MIPv6 UDP throughput

Figure 5 shows the UDP throughput of the test bed during a handover. This indicates that the latency for MIPv6 network with UDP transmission is around 5 seconds. 


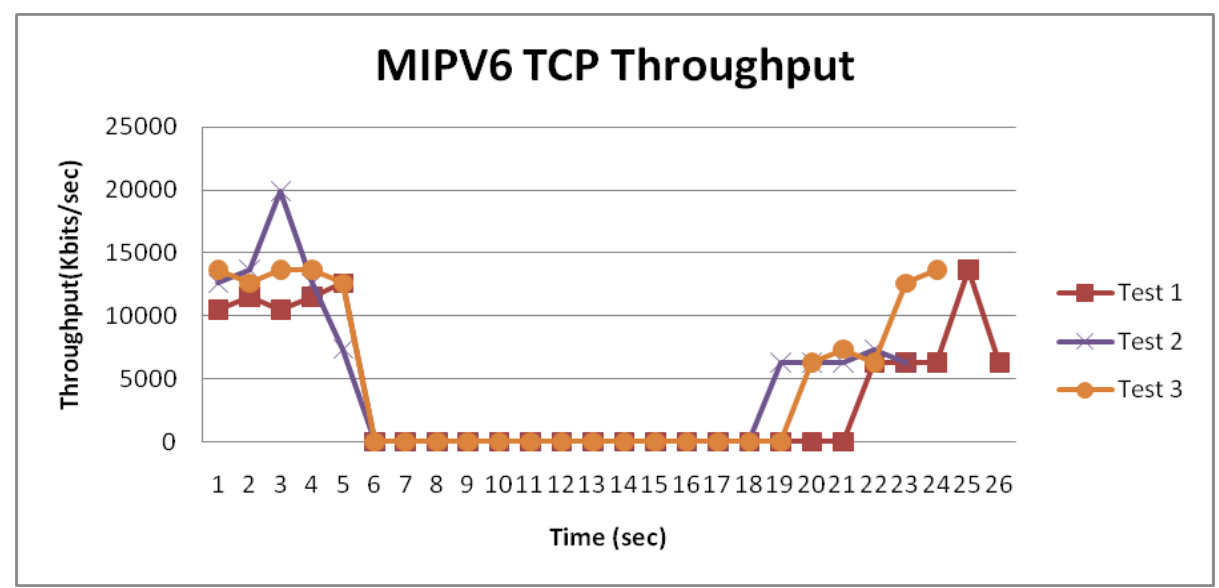

Fig. 6. MIPv6 TCP throughput

Figure 6 shows the TCP throughput of the test bed during a handover, giving a latency for MIPv6 network with TCP transmission around 13 seconds.

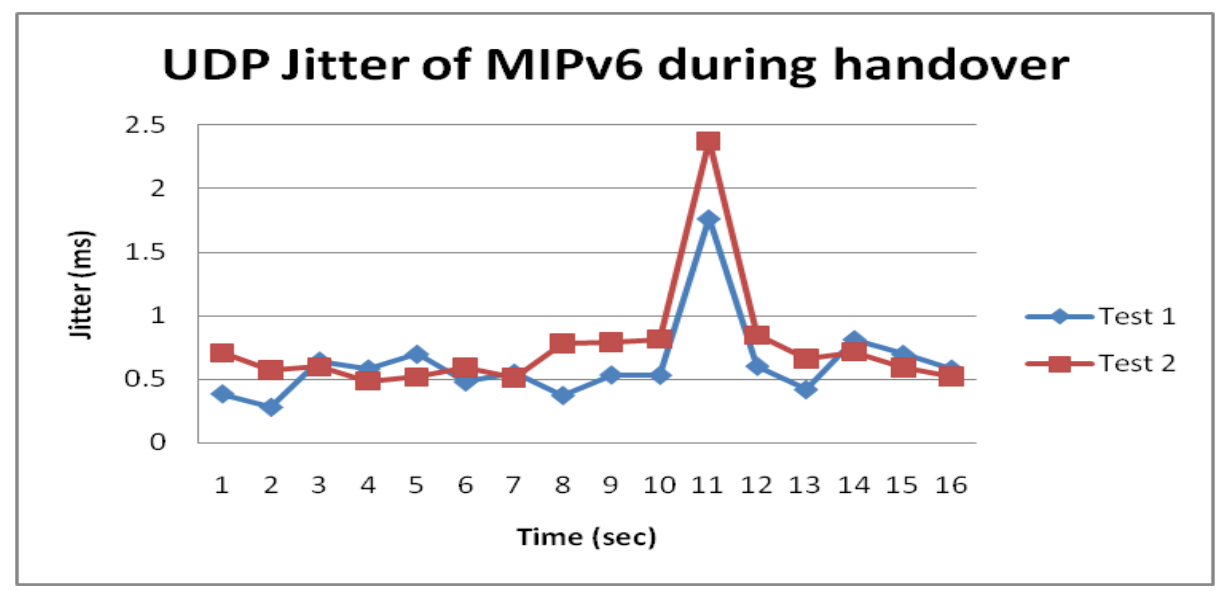

Fig. 7. MIPv6 UDP jitter during handover

Figure 7 shows the UDP jitter of the MIPv6 network. The average UDP jitter for the $10 \mathrm{Mbps}$ is $0.588 \mathrm{~ms}$.

It is clear from the results that MIPv6 handover needs to be optimise to enable effective live video streaming and VOIP during the handover process. 


\subsection{FMIPv6 Test Bed}

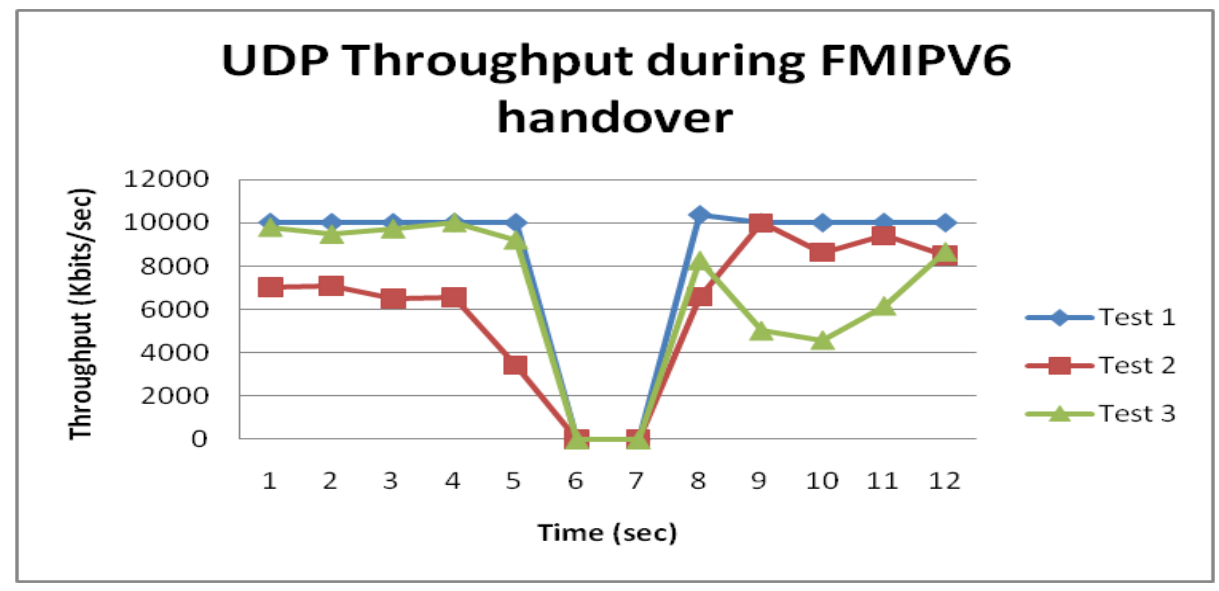

Fig. 8. FMIPv6 UDP throughput

Figure 8 shows the UDP throughput of the test bed during a handover. This indicates that the latency for FMIPv6 network with UDP transmission is around 3 seconds.

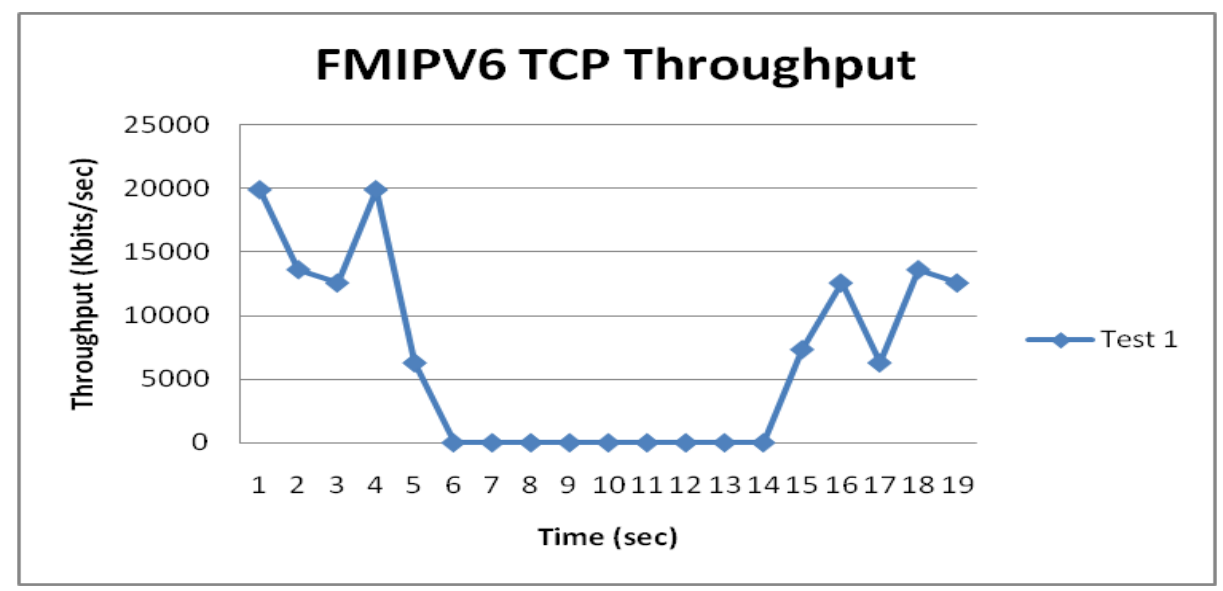

Fig. 9. FMIPv6 TCP throughput

Figure 9 shows the TCP throughput of the test bed during a handover, giving a latency for FMIPv6 network with TCP transmission around 8 seconds. 


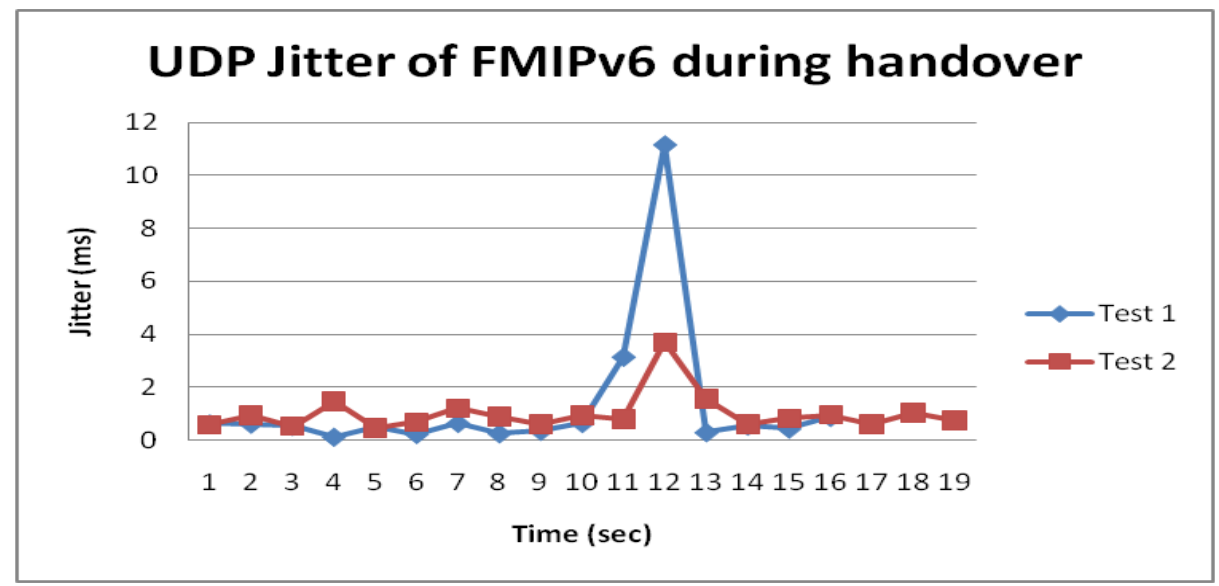

Fig. 10. FMIPv6 UDP jitter during handover

Figure 10 shows the UDP jitter of the FMIPv6 network. The average UDP jitter for the $10 \mathrm{Mbps}$ is $1.01 \mathrm{~ms}$.

\subsection{MIPv6 and FMIPv6 Comparison}

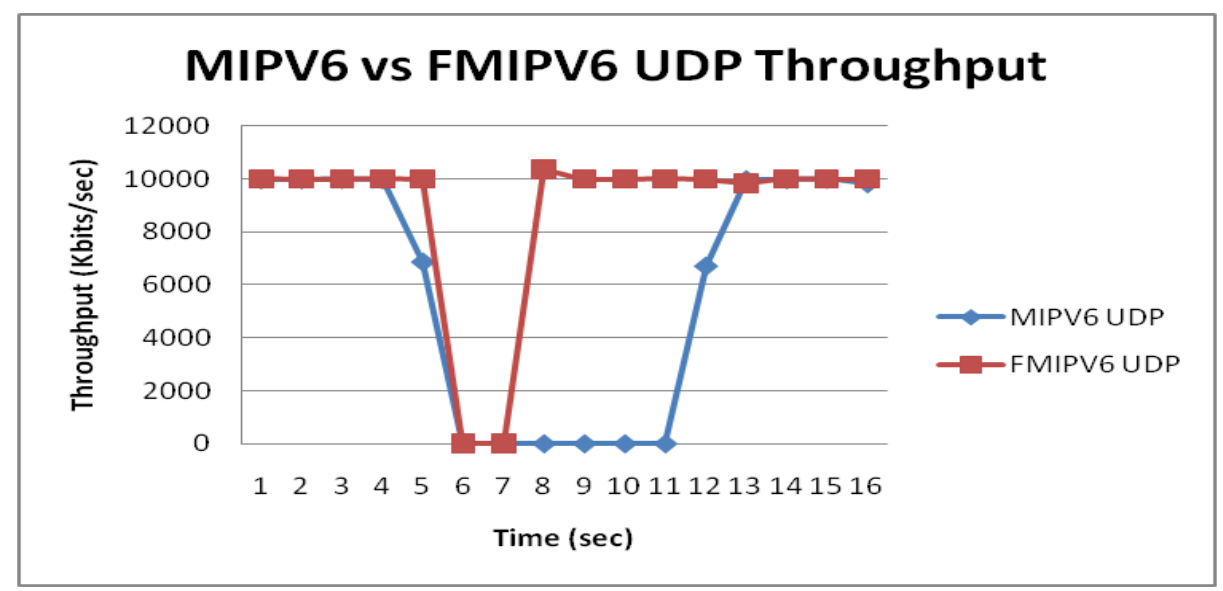

Fig. 11. MIPv6 vs FMIPv6 UDP throughput

We find that the FMIPv6 in predictive mode supports a faster handover, and thus reduces the handover latency of the network. The total handover time of MIPv6 is 5 seconds and FMIPv6 in predictive handover is minimum 3 seconds, resulting in a significantly lower latency time in the network. 


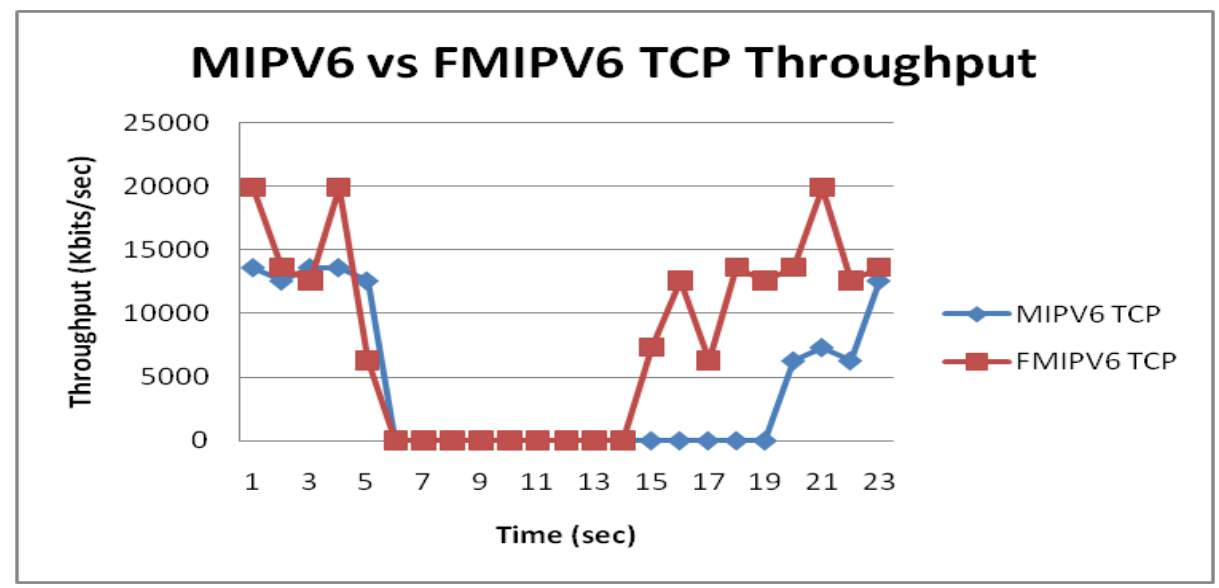

Fig. 12. MIPv6 vs FMIPv6 TCP throughput

We find that the FMIPv6 in predictive mode supports a faster handover, and thus reduces the handover latency of the network. The total handover time of MIPv6 is 13 seconds and FMIPv6 in predictive handover is minimum 8 seconds. The FMIPv6 reported a better performance due to a lower latency during handover process.

\section{Summary and Conclusion}

Table 2 shows the total handover time of MIPv6 and FMIPv6. From the results in Section 5 and Table 2 we can conclude that FMIPv6 performs well when compared with MIPv6 and is suitable to be used for real time applications, such as VOIP and video streaming.

Table 2. Total handover time of MIPv6/FMIPv6 Test Bed

\begin{tabular}{|c|c|}
\hline Protocol & Handover time (Sec) \\
\hline MIPv6 TCP & 13 \\
\hline FMIPv6 TCP & 8 \\
\hline MIPv6 UDP & 7 \\
\hline FMIPv6 UDP & 3 \\
\hline
\end{tabular}

For UDP throughput and jitter comparison, the UDP throughput as per Figure 11 shows that FMIPv6 in predictive mode also performs better than MIPv6. For comparison of UDP jitter, Figure 7 and Figure 10 show the comparison of average UDP jitter of the two protocols. In Table 3, we see the average UDP jitter calculated in Jperf for the two protocols. The UDP jitter for MIPv6 is 0.588 and 1.01 for FMIPv6. This indicates that MIPv6 has the minimal jitter of 
the two protocols. The reason for this result is the way that FMIPv6 is deployed. When running FMIPv6 the MIPv6 daemon also needs to run and this means that the number of processes on the FMIPv6 nodes will be more than on the MIPv6 nodes.

Table 3. Average UDP Jitter (ms) of MIPv6/FMIPv6 Test Bed

\begin{tabular}{|c|c|}
\hline Protocol & Average UDP Jitter (ms) \\
\hline MIPv6 UDP & 0.588 \\
\hline FMIPv6 UDP & 1.01 \\
\hline
\end{tabular}

Further tests on the MIPv6 and FMIPv6 protocols will include various router advertisement time intervals and file transfer using a FTP application. The sought for results would be the packet loss during handover with different file sizes and the average transmission time of FTP applications. The router advertisements will be changed to see the effect on the handover latency of the protocols. To measure the video quality performance of the protocols, the network will also be tested using Jinzora Media Server with Mean Opinion Score (MOS) used to evaluate transmission quality [10].

In summary, the FMIPv6 protocol outperforms the MIPv6 in all aspects. However the implementation of the FMIPv6 protocol still has several limitations and still requires refinement, but this does not affect the test results. For example, after a while of running FMIPv6, the MN will disconnect and the performance of the network will slow down. We also find a lot of packets being dropped when the MN needs to scan for neighbouring AP's, but adding an additional wireless card to the MN resolves this problem. We look forward to further improvements of FMIPv6.

\section{References}

1. R. Prasad and S. Dixit, Eds., Wireless IP and Building the Internet, ser. The Artech House Universal Personal Communications Series. Artech House, 2003.

2. G. Xie, J. Chen, H. Zheng, J. Yang, and Y. Zhang. Handover latency of mipv6 implementation in linux. [Online]. Available: http://ieeexplore.iee.org/stamp/ stamp.jsp?tp=\&arnumber $=4411253$

3. J. Chandrasekaran, "Mobile ip: Issues, challenges and solutions," Master's thesis, Department of Electrical and Computer Engineering Rutgers University, 2009.

4. "Mobility support in ipv6," June 2004. [Online]. Available: http://www.ietf.org/ rfc/rfc3775.txt

5. P. NGAMTURA, "Performance comparison of mipv6 and fmipv6 over wlans," Master's thesis, FACULTY OF GRADUATE STUDIES MAHIDOL UNIVERSITY, 2010. [Online]. Available: www.li.mahidol.ac.th/thesis/2553/ cd439/4737231.pdf 
6. "Enhanced route optimization for mobile ipv6," May 2007. [Online]. Available: http://www.ietf.org/rfc/rfc4866.txt

7. F. Z. Yousaf, C. Bauer, and C. Wietfeld, "An accurate and extensible mobile ipv6 (xmipv6) simulation model for omnet++," in 1st International Conference on Simulation Tools, March 2008.

8. "Umip: Usagi-patched mobile ipv6 for linux." [Online]. Available: http: //umip.linux-ipv6.org/index.php?n=Main.HomePage

9. JPerf. [Online]. Available: http://sourceforge.net/projects/jperf/

10. "Mean opinion score." [Online]. Available: http://en.wikipedia.org/wiki/Mean_ opinion_score 